\title{
Modern methods of development of marine gas hydrate deposits
}

\author{
V. I. Bondarenko ${ }^{1}$, I. A. Kovalevska ${ }^{1}$ and K. M. Prokopenko ${ }^{1}$ \\ ${ }^{1}$ Dnipro University of Technology, Department of Mining Engineering and Education, \\ Dnipro, Ukraine \\ E-mail: v_domna@yahoo.com
}

\begin{abstract}
Abs tract. In recent years, there has been a trend around the world towards a constant increase in the consumption of fuel and energy resources, in connection with this there is a significant increase in interest in non-traditional methods of extraction of various energy sources. For many countries, this issue is especially relevant, since the price of natural gas supplied from abroad is growing every year, which negatively affects the economy. Therefore, the need to modernize the structure of the oil and gas complexes and to improve the mechanism for the development of the energy segment, which is possible through the introduction and application of the latest gas hydrate technologies, which will provide an opportunity to obtain additional energy, is obvious.
\end{abstract}

\section{Introduction}

Gas hydrates are ice-crystalline compounds that consist of water and natural gas molecules. These are so-called inclusion compounds: water molecules bond to each other with hydrogen bonds and form scaffolds with spacious cavities inside. Chemical bonds between gas and water molecules are not formed, the molecules are held only by weak intermolecular Van-der-Waals forces [1].

The properties of gas hydrates are unique. One volume of water, when converted to hydration, binds up to 200 volumes of methane. In this case, its specific volume increases by $26 \%$ (with freezing water its specific volume increases by only $9 \%$ ). $1 \mathrm{~m}^{3}$ of methane hydrate at a pressure of $2.63 \mathrm{MPa}$ and a temperature of $0{ }^{\circ} \mathrm{C}$ contains 164 volumes of gas. At the same time, gas accounts for $0.2 \mathrm{~m}^{3}$, and water for $0.8 \mathrm{~m}^{3}$ [2]. During the periods of gas hydrates research, it has been found that such components of natural gas as $\mathrm{CH}_{4}, \mathrm{C}_{2} \mathrm{H}_{6}, \mathrm{C}_{3} \mathrm{H}_{8}, \mathrm{C}_{4} \mathrm{H}_{10}, \mathrm{CO}_{2}, \mathrm{~N}_{2}, \mathrm{H}_{2} \mathrm{~S}$ etc., form both individual and mixed hydrates (their composition includes several gases) [3].

Almost all hydrophobic gases and volatile liquids the size of molecule of $3.8-9.2 \AA$ can create gas hydrates, as well as some hydrophilic compounds that have sufficiently weak interaction with water, which do not prevent clathrate formation [4].

Searching programs and research centers for the study of gas hydrates have been established in many countries today, as hydration gas production will help solve the world's energy problem. However, it is extremely important to develop and apply techniques and technologies for the development of gas hydrate deposits and the production of methane gas [5]. Gas hydrate field development technologies are linked to the physicochemical properties of these clathrate compounds and rely on dissociation to disperse gas hydrates into gas and water. It is possible to release gas contained in hydrates by shifting the equilibrium parameters of their stable existence [6].

Methods for the development of gas hydrate deposits are based on the laws of existence of gas hydrates and their properties. 


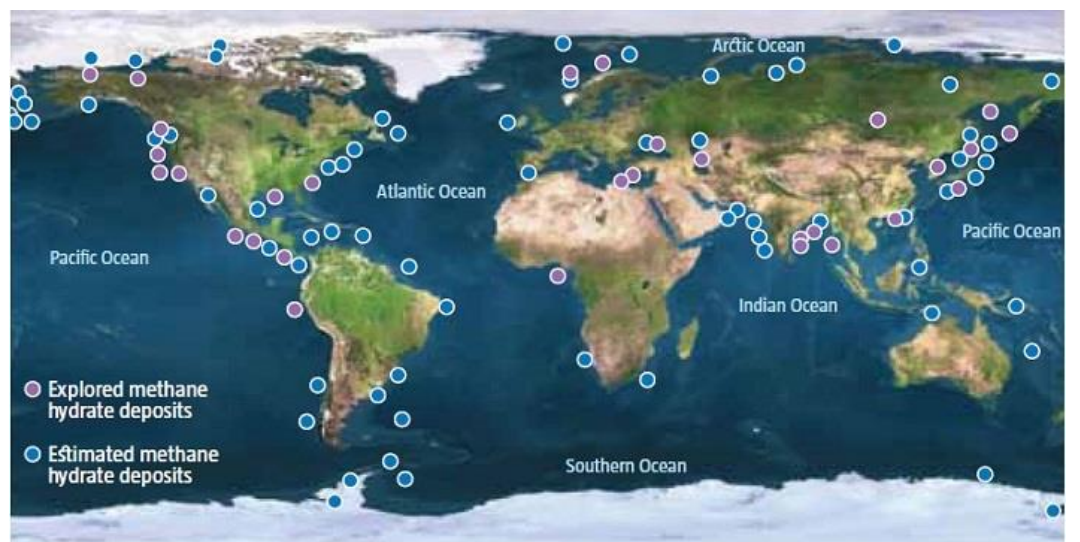

Figure 1 - Global distribution of gas hydrates (courtesy of Council of Canadian Academies (2008), based on data from Kvenvolden and Rogers (2005)).

First, it is taken into account that all the reserves are located mainly in the deep zones. Second, gas hydrates exist under relatively high pressure and low temperatures [7], [8]. Water molecules are bonded by a hydrogen bond that easily breaks down under reduced pressure and fever. These two main characteristics are based on modern methods of gas production from gas hydrates.

\section{Literature review}

The issues of deposits development, related directly to the consideration of geological structure, are constantly actual for all types of minerals [9], [10], [11]. The gas hydrate deposits of high priority and that suitable for development can be chosen according to the principle proposed in the work [12].

An undeniable advantage of gas extraction from gas hydrates is the absence of industrial waste as a result of mining operations, unlike the traditional development technologies, the use of which forms on the daylight surface numerous mine rock accumulations in dumps [13].

There are three main methods of gas extraction from gas hydrates [14]:

- thermal method based on deposit heating;

- depressive method, which is to reduce the pressure in the gas hydrate;

- method of substitution or addition of chemicals that are catalysts for the process of gas hydrate deposit dissociation.

\section{A. Thermal Stimulation}

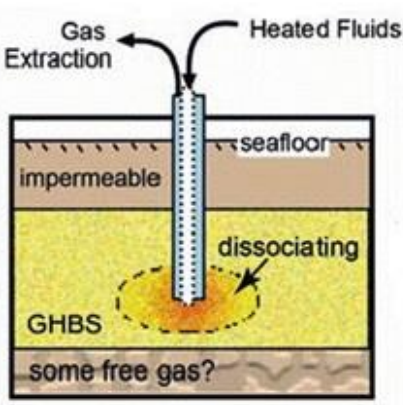

B. Depressurization

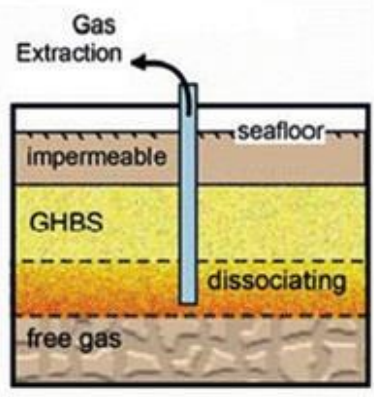

C. Additive Injection

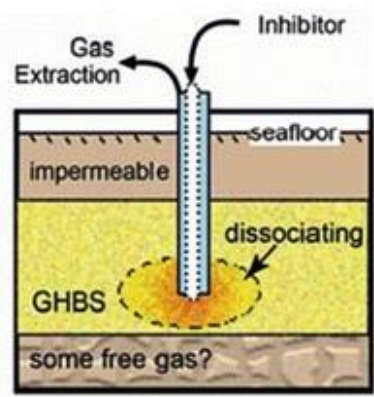

Figure 2 - Methods for gas hydrate deposits development and natural gas production (Kollett, L'yuis, \& Uchida, 2001; Ersland \& Graue, 2010).

The essence of the thermal method is based on the flow of heat inside the crystalline lattice of the gas hydrate in order to raise the temperature and start the dissociation process by pumping the coolant into the gas-gaseous deposit. Warm seawater or steam can act as the coolant. The coolant is pumped 
into the gas-hydrate reservoir through the injection well, and the released gas exits the operating well and is trapped on the surface [15], [16].

The depressing gas extraction method (depressurization) consists in artificially reducing the reservoir pressure around the well below the equilibrium, which is achieved by reducing the pressure in the well or by reducing the water or free gas pressure on the gas hydrate after partial pumping. When the pressure in the gas layer is lower than the gas hydrate phase equilibrium, the gas hydrate decomposes into gas and water, while absorbing the thermal energy of the environment [17].

The method of substitution or addition of chemicals is based on the shift of the phase equilibrium of the gas hydrate, which leads to its decomposition. The replacement is the displacement of methane from the "cells" of clathrates by filling them with another gas, for example, carbon dioxide. Methanol, glycol, ethanol, brine, etc. can be used as chemicals used in the development of gas hydrate deposits. There are several subspecies of this type of method [18].

Modern methods include:

- using of nanoparticles for the destruction of gas hydrates

- microwave heating of the gas hydrate field

The destruction efficiency of gas hydrates depends on the shape of the nanoparticles: in particular, on the presence of spherical nanoparticles of various spikes arranged uniformly over their entire surface [19], [20].

Optimal parameters (length, distance between them, etc.) and shape (rectilinear, curved, thickened, etc.) of spherical nanoparticle spikes are also important for the efficient provision of the destruction process of the clathrate cell with the methane molecule included in it [21].

Such nanostructures, which look like natural biological objects - sea urchins, are quite easily formed by the electrochemical method. Currently, the main material for their construction is polystyrene [22].

The polystyrene microsphere is the basis on which zinc oxide forms a three-dimensional surface. The result is hollow, spherical nanostructures with spikes sticking out in all directions.

The development provides for the gradual destruction of the upper layer of gas hydrate accumulations by hydrodynamic jet of seawater pre-saturated with spherical nanoparticles. When the spherical particle moves along the surface of the crystalline cell of the gas hydrates, its destruction and release of the methane molecule occur. In this way, a solution of methane and its homologs is formed, the extraction of which is carried out forcibly first on the surface and then due to the gas lift effect [23].

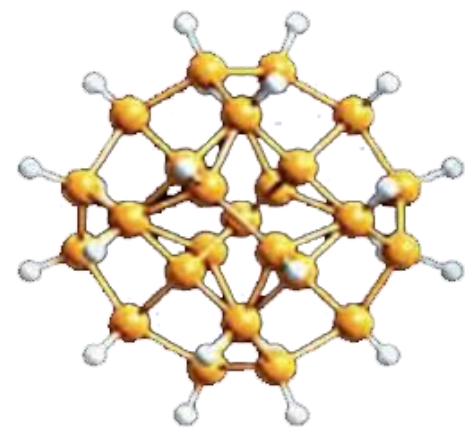

Figure 3 - Nanoparticles with spikes for the destruction of gas hydrates (Vorob’yev, A. E. (2016))

In addition to spherical nanoparticles, it is more expedient to use various molecular gears and axially connected wheels as a working tool to destroy hydrate deposits. Models of such nano-devices were proposed by K.E. Drexler and R. Merkle of IMM (Institute for Molecular Manufacturing, Palo Alto).

The shafts of the gears in this gearbox are carbon nanotubes, and the "teeth" are benzene molecules. In this case, the characteristic speeds of the gears are several gigahertz [23].

In conventional heat transfer processes, energy is carried to the material via convection, conduction and radiation because of thermal gradients. But, in microwave energy is passed directly to materials 
through their molecular interaction with the electromagnetic field. Microwave heating is the change of electromagnetic energy to thermal energy. Microwaves can pass through materials and deposit energy; heat can be created throughout the volume of the material. So, it can decrease processing times and prove to be energy efficient [24].

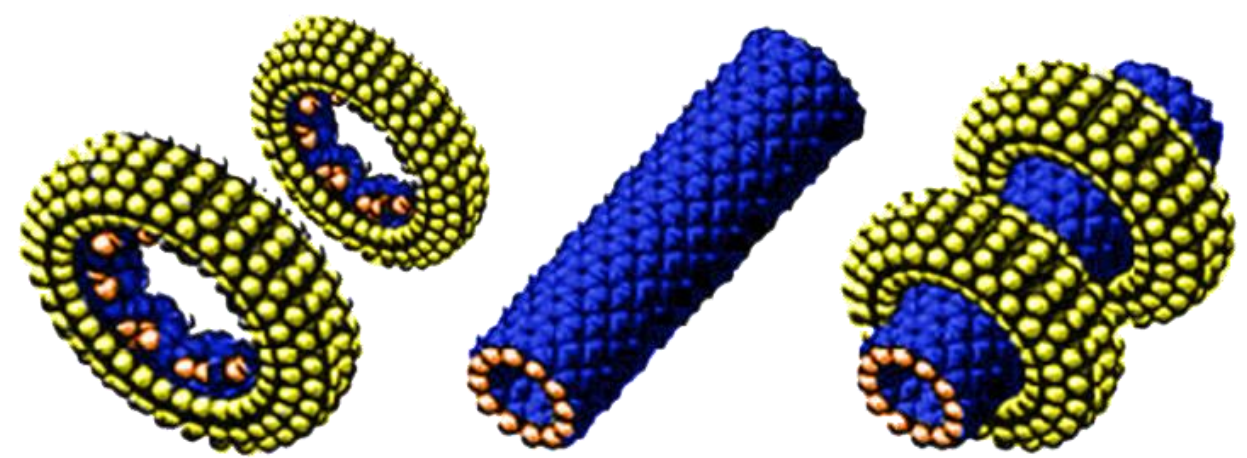

Figure 4 - Nanotubes for the destruction of gas hydrates (K.E. Drexler and R. Merkle)

Petroleum industry has used microwave irradiation recently [25].

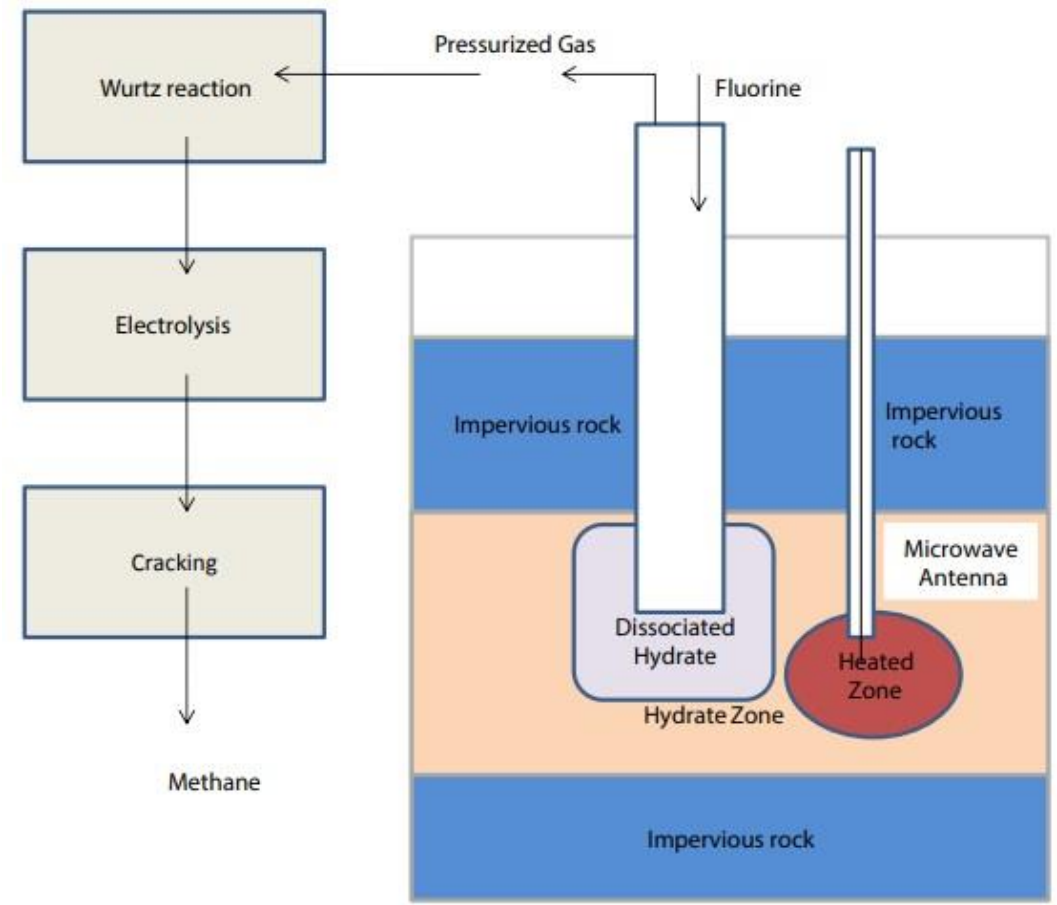

Figure 5 - Gas extraction using the microwave technique (Garg R, Ogra K, Choudhary A, Menezes, R (2008))

The exploitation of natural gas hydrate (NGH) for the recovery of gas since possible via heating and microwaves are also gaining attention as heating media in oil and gas industry. The decomposition of hydrates with microwaves was studied by Rogers [26]. While this experiment, the power of microwave was increased gradually. The results showed that microwave heating was very prominent method for hydrate dissociation. Other groups reported experimental studies on the dissociation of propane hydrate by microwave are Fatykhov et al. [27]. The kinetics of methane hydrate crystallization using molecular dynamics simulation in the presence of microwave is reported by English et al. [28]. It was concluded that NGH will dissociate when the intensity was more than a certain value, because the movement of the molecules in the system was increased by microwave [29]. 


\section{Propose d technology}

According to the authors, microwave exposure technology is promising, since it has the following advantages compared to traditional approaches to the destruction of gas hydrates.

- The amount of energy spent on generating a microwave wave is approximately equal to the amount of energy delivered to the reservoir, therefore, energy losses during wave transmission are minimal.

- The problem of re-hydrate formation is almost eliminated due to in-line heating of the well.

- The controllability of the hydrate destruction process is achieved by the duration of exposure, as a result of which a sudden chain reaction of destruction is prevented.

- Safety for the environment is achieved by the fact that the spread of microwave waves at a depth below the seabed is suppressed by the soil, as a result of which the waves do not spread to the world ocean.

Based on the studied material, a technological scheme for the extraction of natural gas from gas hydrates was developed and proposed.

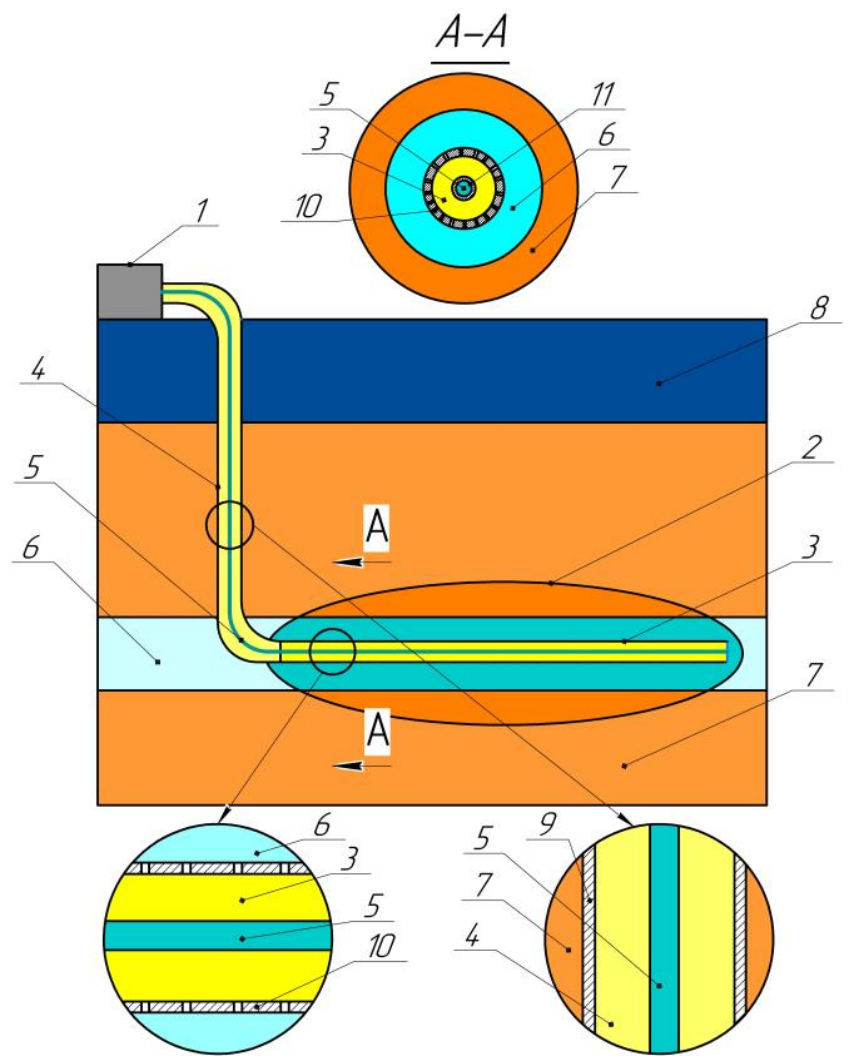

Figure 6 - Technological scheme for the extraction of natural gas from gas hydrates was developed and proposed.

The method of decomposition and production of natural gas hydrates of hydrocarbon gases, or mixtures thereof from offshore fields by exposure to ultra-high frequency (microwave) radiation is carried out as follows. From the platforms above the marine space " 8 " drill a vertical section of the well "4" in the reservoir of gas hydrate deposit "6", which lies between the layers of associated rocks "7". In the process of implementation of the method, the vertical section of the well "4" performs both discharge and productive. When approaching the place of occurrence of gas hydrates, using directional drilling, the vertical section of well " 4 " is bent and carried along the productive layer of gas hydrate deposit "6". After the bend, the horizontal section of the well "3" has a perforation "10", which is able to pass electromagnetic microwave waves, the size and number of holes which are set in advance. The 
microwave radiation system "1" is connected to the vertical section of the well "4", which sends electromagnetic wave oscillations through the waveguide "5", which runs along the whole well. Waveguide "5" in the horizontal section of the well "3" through the holes of the perforation "10" emits electromagnetic microwave waves into the gas hydrate deposit "6" creating a field of influence of microwave waves "2". The created field of microwave waves "2" warms the gas hydrate deposit "6" by destroying the crystal lattice of the hydrate that holds the gas. The released gas is pumped to the surface through the perforation "10" of the horizontal section of the well "3" on the way back.

The microwave radiation system "1" is shielded with a casing to protect people and the environment from electromagnetic microwave waves. To achieve maximum efficiency of the method microwave radiation system "1" is placed near the mouth of the vertical section of the well "4".

Directional drilling allows you to set the angle of the drill string for longitudinal drilling of gas hydrate deposit "6", which does not necessarily lie horizontally and has a certain angle. The horizontal section of the well "3" centrally carried out on the layer of gas hydrate deposit "6" for uniform comprehensive action of the field of influence of microwave waves "2". The accompanying rocks "7", including sediments, which close the gas hydrate deposit "6", serve as a sealed barrier and prevent the microwave radiation from spreading uncontrollably into the marine space "8".

The microwave radiation system "1" generates microwaves when interacting with the flow of electrons with the electric component of a high-frequency field in space, where a constant magnetic field is perpendicular to a constant electric field. Waveguide "5" is represented by a tube capable of propagating microwave waves generated by the microwave radiation system " 1 ". The size of the waveguide is set depending on the frequency of the wave. The solid walls of the well 9 prevent microwaves from spreading into the marine space 8 and protect the environment from the effects of microwave radiation. At the stage of gas production, waveguide " 5 " has additional use, it prevents the formation of gas hydrate plugs in the vertical section of well "4". The walls of waveguide "11" are heated, creating in the vertical section of the well "4" such conditions that exclude the possibility of nucleation of hydrates.

At the initial stage, mining and geological conditions of the occurrence of the gas hydrate deposit " 6 " are pre-determined. Based on the parameters of temperature, pressure and height of the gas hydrate reservoir "6", regardless of the composition of the gas, set the output power of the microwave radiation system "1", which can be adjusted in the production process. The intensity of the influence of microwave waves is determined by the intensity of the process of extracting gas from the layer of gas hydrate deposit "6", which is controlled by adjusting the parameters of the system of microwave radiation "1". The production process is continuous and runs in the process of longitudinal drilling of the productive reservoir of gas hydrate deposit "6", and the homogeneous field of influence of microwave waves "2" comprehensively propagate in parallel with the drilling process. The rate of passage of the gas hydrate deposit "6" is controlled by the gas release parameter, which gives the opportunity to influence the efficiency of the discharge.

In a continuous extraction process to release gas from the hydrate by electromagnetic microwave radiation, they affect water molecules, heating them and destroying the crystal lattice of hydrates. Based on the parameters of the temperature and pressure of the gas hydrate deposit "6", in the process of hydrate decomposition, the necessary degree of heating is applied within the homogeneous field of influence of microwave radiation "2", breaking the balance in which gas hydrates lie. For the destruction of the crystal lattice of the gas hydrate, a slight rise in temperature is determined, which is determined relative to the pressure parameter in the gas hydrate deposit "6", which allows locally to influence the formation without affecting the associated rocks "7" and to save energy.

\section{Conclusions}

- Modern technologies are developing every day, which allows us to state with confidence that soon the need for additional sources of hydrocarbon fuel will become more widespread. As an additional fuel resource, according to the authors, it is possible to consider gas hydrates. 
- All existing technologies for the development of gas hydrate deposits are not ideal, with their advantages and disadvantages, however, according to the authors, the proposed technology is safer for the environment among all considered.

- The authors believe that to create more efficient and productive technologies for the development of gas hydrate deposits, quintessence of various industries and fields of science, as well as a comprehensive study of a single field are necessary.

\section{References}

[1] Carroll, J. (2014). Hydrate Types and Formers. Natural Gas Hydrates, 23-57. doi:10.1016/b978-0-12-800074-8.00002-8

[2] Boswell, R. (2009). Is Gas Hydrate Energy Within Reach? Science, 325(5943), 957-958. doi:10.1126/science. 1175074

[3] Bondarenko, V., Kovalevska, I., Astafiev, D., \& Malova, O. (2018). Examination of Phase Transition of Mine Methane to Gas Hydrates and their Sudden Failure - Percy Bridgman's Effect. Solid State Phenomena, 277, 137-146. doi:10.4028/www.scientific.net/ssp.277.137

[4] Sai, K., Malanchuk, Z., Petlovanyi, M., Saik, P., \& Lozynskyi, V. (2019). Research of Thermodynamic Conditions for Gas Hydrates Formation from Methane in the Coal Mines. Solid State Phenomena, 291, 155-172. doi:10.4028/www.scientific.net/ssp.291.155

[5] Bondarenko, V. I., \& Sai, K. S. (2018). Process pattern of heterogeneous gas hydrate deposits dissociation. Naukovyi Visnyk Natsionalnoho Hirnychoho Universytetu, (2), 21-28. doi:10.29202/nvngu/2018-2/4

[6] Maksymova, E. (2015). Methodological approach to the development of gas hydrate deposits. New Developments in Mining Engineering 2015, 129-132. doi:10.1201/b19901-24

[7] Ovchynnikov, M., Ganushevych, K., \& Sai, K. (2013). Methodology of gas hydrates formation from gaseous mixtures of various compositions. Mining of Mineral Deposits, 203-206. doi:10.1201/b16354-36

[8] Bondarenko, V., Sai, K., Ganushevych, K., \& Ovchynnikov, M. (2015). The results of gas hydrates process research in porous media. New Developments in Mining Engineering 2015, 123-127. doi:10.1201/b19901-23

[9] Sekerin, V., Dudin, M., Gorokhova, A., Bank, S., \& Bank, O. (2019). Mineral resources and national economic security: current features. Mining of Mineral Deposits, 13(1), 72-79. doi:10.33271/mining13.01.072

[10] Saik, P., Petlovanyi, M., Lozynskyi, V., Sai, K., \& Merzlikin, A. (2018). Innovative Approach to the Integrated Use of Energy Resources of Underground Coal Gasification. Solid State Phenomena, 277, 221-231. doi:10.4028/www.scientific.net/ssp.277.221

[11] Kirin, R. (2019). Statutory and regulatory requirements in the process of mineral mining in Ukraine. Review and analysis. Mining of Mineral Deposits, 13(2), 59-65. doi:10.33271/mining13.02.059

[12] Petlovanyi, M.V., \& Medianyk, V.Y. (2018). Assessment of coal mine waste dumps development priority. Naukovyi Visnyk Natsionalnoho Hirnychoho Universytetu, (4), 28-35. doi:10.29202/nvngu/2018-4/3

[13] Popovych, V., Kuzmenko, O., Voloshchyshyn, A., \& Petlovanyi, M. (2018). Influence of manmade edaphotopes of the spoil heap on biota. E3S Web of Conferences, 60, 00010. doi:10.1051/e3sconf/20186000010

[14] Kumar, R., \& Linga, P. (2017). Gas Hydrates. Encyclopedia of Engineering Geology, 1-7. doi:10.1007/978-3-319-39193-9_177-1

[15] Bondarenko, V., Ganushevych, K., Sai, K., \& Tyshchenko, A. (2011). Development of gas hydrates in the Black sea. Technical and Geoinformational Systems in Mining, 55-59. doi:10.1201/b1 1586-11

[16] Yun, Z., Jianfang, S., \& Zhongchun, L. (2019). Study of numerical simulation method modelling gas injection into fractured reservoirs. Mining of Mineral Deposits, 13(2), 41-45. 
doi:10.33271/mining13.02.041

[17] Swaranjit Singh, A. A. (2015). Natural Gas Hydrate as an Upcoming Resource of Energy. Journal of Petroleum \& Environmental Biotechnology, 06(01). doi:10.4172/2157-7463.1000199

[18] Processes for Methane Production from Gas Hydrates. (2010). Green Energy and Technology, 161-181. doi:10.1007/978-1-84882-872-8 5

[19] Bondarenko, V., Svietkina, O., \& Sai, K. (2017). Study of the formation mechanism of gas hydrates of methane in the presence of surface-active substances. Eastern-European Journal of Enterprise Technologies, 5(6 (89)), 48-55. doi:10.15587/1729-4061.2017.112313.

[20] Bondarenko, V., Svietkina, O., \& Sai, K. (2018). Effect of mechanoactivated chemical additives on the process of gas hydrate formation. Eastern-European Journal of Enterprise Technologies, 1(6 (91)), 17-26. doi:10.15587/1729-4061.2018.123885

[21] Bondarenko, V., Svietkina, O., Sai, K., \& Klymenko, V. (2018). Investigation of the influence of polyelectrolytes hydrodynamic properties on the hydrateformation process. E3S Web of Conferences, 60, 00007. doi:10.1051/e3sconf/20186000007

[22] Vorob'yev, A. E. (2016). Prospects of nanotechnologies of developing gaseous-hydrate resources of the Russian Arctic shelf. Vestnik MGTU, 19(1/1), 70-81. doi:10.21443/15609278-2016-1/1-70-81

[23] Drexler, K. E. (2004). Different paths to the nano-scale. Physics World, 17(10), 18-18. doi:10.1088/2058-7058/17/10/23

[24] Thostenson, E. T., \& Chou, T.-W. (1999). Microwave processing: fundamentals and applications. Composites Part A: Applied Science and Manufacturing, 30(9), 1055-1071. doi:10.1016/s1359-835x(99)00020-2

[25] Xia, L., Lu, S., \& Cao, G. (2003). Demulsification of Emulsions Exploited by Enhanced Oil Recovery System. Separation Science and Technology, 38(16), 4079-4094. doi:10.1081/ss120024720

[26] R.E. Rogers. (1999). NATURAL GAS HYDRATES STORAGE PROJECT. doi: $10.2172 / 760130$

[27] Fatykhov, M. A., \& Bagautdinov, N. Y. (2005). Experimental Investigations of Decomposition of Gas Hydrate in a Pipe under the Impact of a Microwave Electromagnetic Field. High Temperature, 43(4), 614-619. doi:10.1007/s10740-005-0103-7

[28] English, N. J., \& MacElroy, J. M. D. (2004). Theoretical studies of the kinetics of methane hydrate crystallization in external electromagnetic fields. The Journal of Chemical Physics, 120(21), 10247-10256. doi:10.1063/1.1730092

[29] Swaranjit Singh, A. A. (2015). Techniques for Exploitation of Gas Hydrate (Clathrates) an Untapped Resource of Methane Gas. Journal of Microbial \& Biochemical Technology, 07(02). doi:10.4172/1948-5948.1000190 